\title{
Single administration of Selective Internal Radiation Therapy versus continuous treatment with sorafeNIB in locally advanced hepatocellular carcinoma (SIRveNIB): study protocol for a phase iii randomized controlled trial
}

Mihir Gandhi ${ }^{1,2,3}$, Su Pin Choo ${ }^{4}$, Choon Hua Thng ${ }^{5}$, Say Beng Tan ${ }^{6,7}$, Albert Su Chong Low ${ }^{8}$, Peng Chung Cheow ${ }^{9}$, Anthony Soon Whatt Goh ${ }^{10}$, Kiang Hiong Tay ${ }^{8}$, Richard Hoau Gong Lo ${ }^{8}$, Brian Kim Poh Goh', Jen San Wong ${ }^{9}$, David Chee Eng Ng${ }^{10}$, Khee Chee Soo ${ }^{11}$, Wei Ming Liew ${ }^{12}$, Pierce K. H. Chow ${ }^{9,13,14^{*}}$ (D) and on behalf of Asia-Pacific Hepatocellular Carcinoma Trials Group

\begin{abstract}
Background: Approximately $20 \%$ of hepatocellular carcinoma (HCC) patients diagnosed in the early stages may benefit from potentially curative ablative therapies such as surgical resection, transplantation or radiofrequency ablation. For patients not eligible for such options, prognosis is poor. Sorafenib and Selective Internal Radiation Therapy (SIRT) are clinically proven treatment options in patients with unresectable HCC, and this study aims to assess overall survival following either SIRT or Sorafenib therapy for locally advanced HCC patients.

Methods: This investigator-initiated, multi-centre, open-label, randomized, controlled trial will enrol 360 patients with locally advanced HCC, as defined by Barcelona Clinic Liver Cancer stage B or stage C, without distant metastases, and which is not amenable to immediate curative treatment. Exclusion criteria include previous systemic therapy, metastatic disease, complete occlusion of the main portal vein, or a Child-Pugh score of $>7$. Eligible patients will be randomised 1:1 and stratified by centre and presence or absence of portal vein thrombosis to receive either a single administration of SIRT using yttrium-90 resin microspheres (SIR-Spheres ${ }^{\oplus}$, Sirtex Medical Limited, Sydney, Australia) targeted at HCC in the liver by the trans-arterial route or continuous oral Sorafenib (Nexavar ${ }^{\oplus}$, Bayer Pharma AG, Berlin, Germany) at a dose of $400 \mathrm{mg}$ twice daily until disease progression, no further response, complete regression or unacceptable toxicity. Patients for both the Sorafenib and SIRT arms will be followed-up every 4 weeks for the first 3 months and 12 weekly thereafter. Overall survival is the primary endpoint, assessed for the intention-to-treat population. Secondary endpoints are tumour response rate, time-to-tumour progression, progression free survival, quality of life and down-staging to receive potentially curative therapy. (Continued on next page)
\end{abstract}

\footnotetext{
* Correspondence: pierce.chow.k.h@singhealth.com.sg

${ }^{9}$ Department of Hepato-pancreato-biliary and Transplant Surgery, Singapore

General Hospital, Outram Road, Singapore, Singapore

${ }^{13}$ Office of Clinical, Academic and Faculty Affairs, Duke-NUS Medical School,

8 College Road Singapore, Singapore

Full list of author information is available at the end of the article
} 
(Continued from previous page)

Discussion: Definitive data comparing these two therapies will help to determine clinical practice in the large group of patients with locally advanced HCC and improve outcomes for such patients.

Trial registration: ClinicalTrials.gov identifier, NCT01135056, first received 24, May 2010.

Keywords: Advanced hepatocellular carcinoma, Liver cancer, Radioembolisation, Selective internal radiation therapy, SIR-Spheres, Sorafenib, Systemic therapy, Asia-Pacific, Randomized controlled trial, Phase III

\section{Background}

The incidence and prevalence of hepatocellular carcinoma (HCC) is highly variable in different regions of the world, but the burden is predicted to increase in future years [1]. Approximately $70-80 \%$ of all cases of HCC occur in Asia where it is an important public health concern [2]. Although around $20 \%$ of patients diagnosed with early stage HCC may benefit from potentially curative ablative therapies, such as surgical resection, liver transplantation or radiofrequency ablation [3-5], most patients are diagnosed at an intermediate to advanced stage of $\mathrm{HCC}$, when treatment options are limited and the prognosis poor $[6,7]$. In patients with untreated advanced HCC median survival time is approximately $5-7$ months, although this varies depending on the Child-Pugh score [8-10].

The only systemic therapy shown to confer survival advantage in patients with unresectable advanced HCC is Sorafenib (Nexavar ${ }^{\circ}$, Bayer Pharma AG, Berlin, Germany) [11-13]. In the pivotal Sorafenib Hepatocellular Carcinoma Assessment Randomized Protocol (SHARP) trial in patients with advanced HCC, Sorafenib treatment significantly increased median overall survival (OS) by 2.8 months versus placebo $(10.7$ months versus 7.9 months, respectively; $p<0.001$ ) [6]. A subsequent randomised controlled trial in the Asia-Pacific region confirmed these findings, showing median OS of 6.5 months with Sorafenib treatment versus 4.2 months with placebo $(p<0.014)$ [13]. As a result of these data, Sorafenib is the current recommended first-line treatment for advanced (Barcelona Clinic Liver Cancer [BCLC] stage C) HCC [2]. Effective systemic therapy is an important option for the treatment of HCC in the subset of patients with extrahepatic metastases and Sorafenib resulted in a median OS of 5.7 months in this group [14]. However, the relative benefits of Sorafenib and loco-regional ablative therapy are unclear in the larger group of patients with locally advanced HCC. This is of critical importance since HCC is a fast-growing locally aggressive disease frequently leading to the patient's death before extrahepatic metastases have developed. Consequently, the response of loco-regional disease to first-line therapy determines survival in these patients.

Selective Internal Radiation Therapy (SIRT) with yttrium-90 (Y-90) resin microspheres (SIR-Spheres; Sirtex Medical Limited, Sydney, Australia), is one potential alternative treatment for locally advanced HCC.
SIRT enables targeted delivery of radiation to the tumours, while largely sparing the surrounding liver parenchyma. A meta-analysis showed a high response rate to Y-90 SIRT in HCC patients [15]. Population disparity prevented assessment of OS in this meta-analysis, but cohort studies of patients with HCC receiving SIRT report median OS between 7.0 and 26.3 months [16-25].

Small-scale, retrospective studies have compared SIRT with Y-90 resin microspheres and Sorafenib, and suggest similar median OS in patients with BCLC stage B or C disease $[24,26,27]$, and there are some indications that in patients with locally advanced HCC and portal vein thrombosis (PVT), SIRT is particularly beneficial $[14,22$, 27-29].

However, larger-scale studies are needed to assess this comparison, and therefore, the Selective Internal Radiation Therapy versus sorafeNIB (SIRveNIB) trial has been designed as a prospective, randomized, open-label, multicentre trial to compare median OS in patients with locally advanced HCC receiving either SIRT with Y-90 resin microspheres or Sorafenib.

Another large-scale comparative study of similar design in patients with advanced HCC, SorAfenib versus Radioembolisation in Advanced Hepatocellular carcinoma (SARAH), is ongoing in Europe [30], and these two studies could potentially be combined in a future metaanalysis.

\section{Methods/Design}

Ethics

The SIRveNIB trial will be conducted in accordance with the Declaration of Helsinki and current Good Clinical Practice guidelines, and all participating centres will have obtained the relevant ethics committee approval before patient enrolment.

\section{Eligible population}

The inclusion and exclusion criteria for the SIRveNIB trial are summarised in Table 1 . Informed consent will be obtained from each participant.

\section{Overview of trial design}

SIRveNIB is a prospective, randomized open-label, multicentre trial comparing SIRT and Sorafenib in patients with locally advanced HCC. In SIRveNIB, the aim will be 
Table 1 Patient eligibility criteria for SIRveNIB trial

\begin{tabular}{|c|c|}
\hline Inclusion criteria & Exclusion criteria \\
\hline $\begin{array}{l}\text { - Unequivocal diganosis of locally advanced HCC without extrahepatic } \\
\text { metastases } \\
\text { - Written informed consent provided } \\
\text { - Aged } \geq 18 \text { years } \\
\text { - Patients with HCC that is not amenable to surgical resection, immediate } \\
\text { liver transplantation, or that could be treated with local ablative } \\
\text { techniques (e.g. radiofrequency ablation) } \\
\text { - Locally advanced HCC as defined by BCLC (B) intermediate stage or } \\
\text { BCLC (C) advanced stage } \\
\text { - At least one lesion that can be accurately measured in at least one } \\
\text { dimension (longest diameter to be recorded) as } \geq 10 \mathrm{~mm} \text { with spiral CT } \\
\text { scan or MRI } \\
\text { - ECOG performance status } 0-1 \\
\text { - Adequate haematological function: haemoglobin } \geq 9.5 \mathrm{~g} / \mathrm{dl} \text {, leukocytes } \\
\geq 2500 / \mathrm{mm}^{3}, \text { platelets } \geq 80,000 / \mathrm{mm}^{3}, \text { INR } \leq 2.0 \\
\text { - Adequate kidney function: creatinine }<2.0 \mathrm{mg} / \mathrm{dl} \\
\text { - Adequate hepatic function: albumin } \geq 2.5 \mathrm{~g} / \mathrm{dl} \text {, bilirubin } \leq 2 \mathrm{mg} / \mathrm{dl} \text {; ALP, } \\
\text { AST or ALT } \leq 5 \times \mathrm{ULN} \\
\text { - Liver cirrhosis Child-Pugh A-B (up to } 7 \text { points) } \\
\text { - Life expectancy of at least } 3 \text { months without active treatment }\end{array}$ & $\begin{array}{l}\text { - Patients who have had }>2 \text { administrations of hepatic artery directed } \\
\text { therapy } \\
\text { - Hepatic artery directed therapy }<4 \text { weeks before study entry } \\
\text { - Systemic chemotherapy for HCC, except previous adjuvant or } \\
\text { neoadjuvant therapy given }>6 \text { months before enrollment } \\
\text { - Previous treatment with Sorafenib or VEGF inhibitors } \\
\text { - Previous radiotherapy for HCC or other malignancy } \\
\text { - Intractable ascites, or other clinical signs of liver failure } \\
\text { - Complete thrombosis of the main portal vein } \\
\text { - Extrahepatic metastases, except lung nodules }<1 \mathrm{~cm} \text { or local-regional } \\
\text { lymph nodes }<2 \mathrm{~cm} \text { in greatest diameter } \\
\text { - Clinical signs of central nervous system metastases } \\
\text { - Other concurrent malignancy, except for adequately treated basal cell } \\
\text { or squamous cell skin cancer, in situ cervical cancer, or other cancer for } \\
\text { which the patient has been disease free for } \geq 5 \text { years } \\
\text { - Uncontrolled intercurrent illness } \\
\text { - Contraindications angiograghy to hepatic artery catheterisation: severe } \\
\text { peripheral arterial disease precluding catheterisation, bleeding diathesis } \\
\text { not correctable by standard forms of therapy, portal hypertension with } \\
\text { hepato-fugal flow } \\
\text { - History of allergy to SIR-spheres, Soranefib or related agents } \\
\text { - Patient unable or unwilling to understand or sign the written informed } \\
\text { consent } \\
\text { - Currently enrolled in another investigational therapeutic drug or device } \\
\text { study } \\
\text { - Women, unless postmenopausal or surgically sterile are unwilling to } \\
\text { practice effective contraception } \\
\text { - Men unwilling to use effective contraception during the course of the } \\
\text { study }\end{array}$ \\
\hline
\end{tabular}

ALP alkaline phosphatase, ALT alanine aminotransferase, $A S T$ aspartate transaminase, $C T$ computed tomography, MRI Magnetic resonance imaging, ECOG Eastern Cooperative Oncology Group, HCC hepatocellular carcinoma, INR international normalised ratio, ULN upper limit of normal

to recruit a minimum of 360 patients from a minimum of 15 sites across the Asia-Pacific region.

Eligible patients will be randomized $1: 1$ to receive either systemic therapy with oral Sorafenib or a session of SIRT with SIR-Spheres ${ }^{\oplus}$ (Fig. 1). Randomisation will be stratified by centre and the absence or presence of PVT.

\section{Treatment}

Treatment in the Sorafenib arm will commence within 1 week after randomisation. Patients will receive oral Sorafenib, $400 \mathrm{mg}$ twice daily. Sorafenib treatment will be continued until there is evidence of treatment failure (lack of efficacy resulting in tumour progression at any site determined by CT or MRI scan); there is a cure or complete response and/or the patient undergoes surgical resection, liver transplantation or ablative therapy; unacceptable toxicity occurs; or the patient requests an end to treatment. As published previously, doses may be delayed and/or reduced for clinically significant haematological toxicities and other toxicities or adverse events (AEs) related to study therapy. Dose reductions first to $400 \mathrm{mg} /$ day and then to $400 \mathrm{mg}$ every second day will be allowed, and if further dose reductions are required the patient should be discontinued. For non-haematological AEs other than skin toxicity, treatment will be interrupted for any grade $3 \mathrm{AE}$, and the dose subsequently reduced by one level. For skin toxicity, treatment will be interrupted for any grade 2 or grade $3 \mathrm{AE}$ and a decreased dose frequency or level will be subsequently considered. The dose may be re-escalated once the toxicities or AEs have resolved [31].

Patients randomised to SIRT will receive SIRSpheres at the patient-specific prescribed activity within 35 days after signing of informed consent form, and after the baseline assessment of their suitability for the procedure. The assessment comprises a hepatic angiogram, and a liver-to-lung shunt preassessment with Technetium-99 m ( $\left.{ }^{99 \mathrm{~m}} \mathrm{Tc}\right)$-labelled human serum albumin. The hepatic angiogram will determine the vascular anatomy of the liver in order to plan the optimal delivery of the SIR-Spheres. The ${ }^{99} \mathrm{~m}$ Tc lung-shunt study will assess the presence and degree of lung shunting from the liver. Patients randomised to SIRT, but who are found to be unsuitable for treatment will be included in the SIRT intention to treat analysis. The prescribed activity of SIRSpheres $^{\ominus}$ will be calculated based on the patient's body surface area (BSA) model [32], or the partition model [33]. If the BSA method is used for dose calculation and the percentage lung shunting exceeds $20 \%$ of the hepatic artery blood flow, as determined by $99 \mathrm{~m}$ Tc-scan, the partition model may be used to adjust the prescribed activity so that the radiation absorbed dose to the lungs does not exceed 20 Gy. 


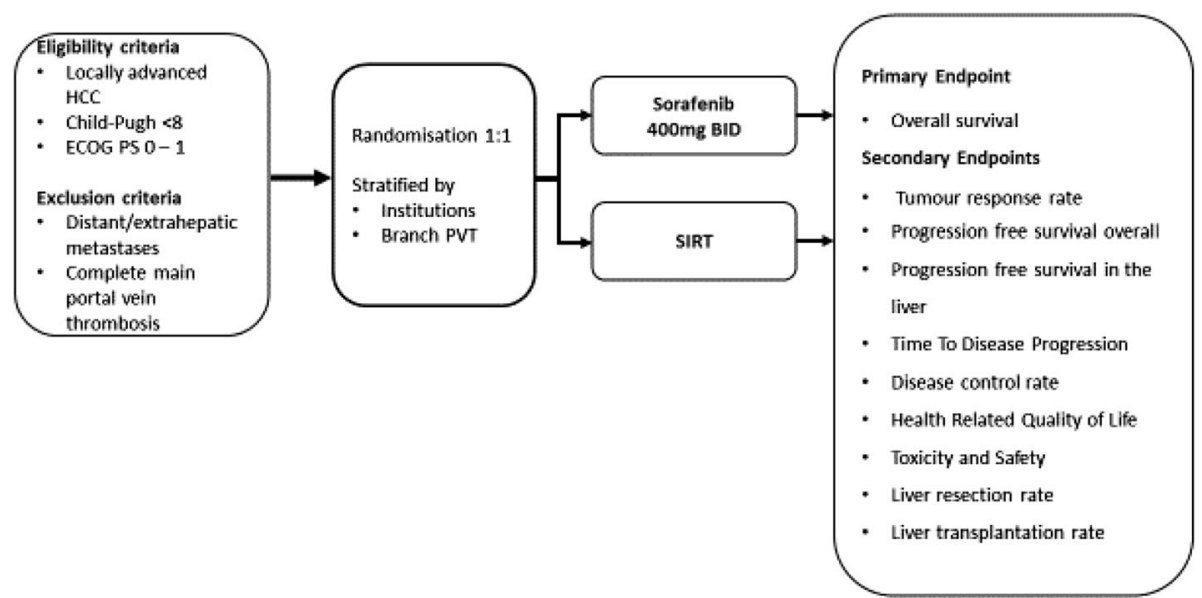

Fig. 1 Overview of the SIRveNIB trial design. ECOG, Eastern Cooperative Oncology Group; PVT, portal vein thrombosis

\section{Assessments}

A quadriphasic contrast-enhanced spiral CT scan of the abdomen/pelvis will be performed at screening to diagnose $\mathrm{HCC}$ according to the American Association for the Study of Liver Diseases (AASLD) criteria [34], determine the extent of liver disease and to exclude extrahepatic abdominal or pelvic metastases. A biopsy positive for $\mathrm{HCC}$ is required for diagnosis if the tumour does not fulfil the AASLD radiological criteria. A thoracic CT scan will be performed to exclude lung metastases. MRI scans will be used in lieu of CT scans in patients for whom CT scanning is not clinically feasible. Each of these CT series will be performed less than 28 days before informed consent is received. All radiology images in this trial will be centrally reviewed by treatmentblinded radiologists at the National Cancer Center Singapore.

All patients will be assessed by the schedule summarised in Table 2. Assessments are at 4-week intervals for the first three months, and then 12-week intervals thereafter. After study conclusion patients will be followed for survival or death at 12-week intervals.

Study conclusion is defined as disease progression, death, complete regression, unacceptable toxicity, patientundergoing surgical resection, liver transplantation or ablative therapy due to a sufficient response with therapy, loss to follow-up, or patient's request for withdrawal.

\section{Outcome measures}

The primary endpoint of the SIRveNIB trial is overall survival (OS). Secondary endpoints include: time to progression (TTP), progression-free survival (PFS), overall and in the liver; tumour response rate (assessed by Response Evaluation Criteria in Solid Tumours [RECIST] version 1.1) [35]; disease control rate; health-related quality of life
(HRQoL); safety and toxicity; and liver resection rate and liver transplantation rate.

\section{Outcome definitions}

- OS - the time from the date of randomisation to death from any cause.

- TTP - the time from the date of randomisation to tumour progression at any site in the body.

- PFS at any site - time from the date of randomisation to tumour progression at any site in the body or death, whichever is earlier.

- PFS in the liver -time from the date of randomisation to tumour progression in the liver or death whichever is earlier.

- Tumour response rate is the number of patients whose best overall response rate (best tumour response over the whole study between randomisation and the last tumour assessment) is partial response (PR) or complete response (CR), divided by the total number of patients in the analysis population.

- Disease control rate - the number of patients whose best overall response is PR, CR or stable disease (SD), divided by the total number of patients in the analysis population.

- HRQoL assessed using the EQ-5D questionnaire.

- Adverse events will be reported according to National Cancer Institute criteria (National Cancer Institute Common Terminology criteria for Adverse Events [NCI CTCAE] Version 4.02) [36].

\section{Sample size calculation and statistical considerations}

Based on OS data reported by Kang et al. 2008 and by Sangro et al. 2010 [14, 37], in patients with locally advanced HCC median survival times of 9.35 months for 
Table 2 SIRveNIB trial assessment schedule

\begin{tabular}{|c|c|c|c|c|c|c|c|c|}
\hline \multirow[t]{2}{*}{ Schedule } & \multirow{2}{*}{$\begin{array}{l}\text { Screening/ } \\
\text { Baseline } \\
\text { (Eligibility) } \\
\text { Randomisation }\end{array}$} & \multicolumn{5}{|c|}{ During Protocol Therapy } & \multirow{2}{*}{$\begin{array}{l}\text { Study } \\
\text { Conclusion } \\
\text { As appropriate }^{c}\end{array}$} & \multirow{2}{*}{$\begin{array}{l}\text { Post Study } \\
\text { Conclusion } \\
\text { Follow-Up } \\
12 \text { weekly }\end{array}$} \\
\hline & & $\begin{array}{l}\text { Week } \\
2^{\mathrm{b}}\end{array}$ & $\begin{array}{l}\text { Week } \\
4\end{array}$ & $\begin{array}{l}\text { Week } \\
8\end{array}$ & $\begin{array}{l}\text { Week } \\
12\end{array}$ & $\begin{array}{l}\text { 12-weekly } \\
\text { thereafter }\end{array}$ & & \\
\hline Informed consent & $x$ & & & & & & & \\
\hline Demographics & $x$ & & & & & & & \\
\hline Medical and surgical history & $x$ & & & & & & & \\
\hline Concurrent illness & $x$ & & & & & & & \\
\hline Concomitant medications & $x^{d}$ & $x^{d}$ & $x^{d}$ & $x^{d}$ & $x^{d}$ & $x^{d}$ & $x^{d}$ & \\
\hline $\begin{array}{l}\text { Clinical assessment \& physical } \\
\text { examination } \\
\text { - Height (Baseline only) } \\
\text { - Weight } \\
\text { - Blood pressure } \\
\text { - Body temperature }\end{array}$ & $x$ & & $x$ & $x$ & $x$ & $x$ & $x$ & \\
\hline $\begin{array}{l}\text { Performance status } \\
\text { - ECOG }\end{array}$ & $x$ & & $x$ & $x$ & $x$ & $x$ & $x$ & \\
\hline $\begin{array}{l}\text { Haematology } \\
\text { - Leukocytes } \\
\text { - Platelets } \\
\text { - Haemoglobin } \\
\text { - INR }\end{array}$ & $x$ & & $x$ & $x$ & $x$ & $x$ & $x$ & \\
\hline $\begin{array}{l}\text { Hepatitis serology } \\
\text { - Hep Bsag } \\
\text { - Anti-HCV IgG } \\
\text { - Hep B Core Antibody } \\
\text { IgG (optional) }\end{array}$ & $x^{e}$ & & & & & & & \\
\hline $\begin{array}{l}\text { Renal function } \\
\text { - Creatinine }\end{array}$ & $x$ & & $x$ & $x$ & $x$ & $x$ & $x$ & \\
\hline $\begin{array}{l}\text { Liver function } \\
\text { - AST/ALT } \\
\text { - ALP } \\
\text { - Total bilirubin } \\
\text { - Albumin }\end{array}$ & $x$ & & $x$ & $x$ & $x$ & $x$ & $x$ & \\
\hline $\begin{array}{l}\text { Pregnancy test } \\
\text { (as appropriate) }\end{array}$ & $x^{f}$ & & & & & & & \\
\hline $\begin{array}{l}\text { Tumour marker } \\
\text { - Serum AFP }\end{array}$ & $x$ & & & & $x$ & $x$ & $x$ & \\
\hline EQ-5D HRQoL & $x$ & & $x$ & $x$ & $x$ & $x$ & $x$ & $x$ \\
\hline $\begin{array}{l}\text { CT or MRI scan: chest/ } \\
\text { abdomen/pelvish, } \mathrm{i}\end{array}$ & $x$ & & & & $x$ & $x$ & & \\
\hline $\begin{array}{l}\text { SIRT-arm ONLY } \\
\cdot \text { Hepatic angiogram } \\
.{ }^{99 \mathrm{~m} T C-\text { MAA lung }} \\
\text { shunt study }\end{array}$ & $x^{g}$ & & & & & & & \\
\hline Response assessment & & & & & $x$ & $x$ & $x$ & \\
\hline Sorafenib arm ONLY & & $x^{b}$ & $x$ & $x$ & $x$ & $x$ & $x$ & \\
\hline
\end{tabular}

- Toxicity assessment

- Dose delay/modification 
Table 2 SIRveNIB trial assessment schedule (Continued)

$\mathrm{AE} / \mathrm{SAE}$

\begin{abstract}
AE/SAE for the Sorafenib arm will be recorded from the time of signing the ICF until 30 days after the final dose of Sorafenib, or until commencement of the next alternative therapy, whichever is earlier.

AE/SAE for the SIRT arm will be recorded from the time of signing the ICF until 30 days post-SIRT regardless of causality and for a further 5 months thereafter if judged by the investigator to be causally related to SIRT or Sir-Spheres, or until commencement of the next alternative therapy, whichever is earlier.

If the AE/SAE is a Sorafenib or SIRT related toxicity follow-up will continue until resolution.
\end{abstract}

Survival $X$

${ }^{\mathrm{a}}$ Screening assessments performed within 28 days before signing of informed consent can be used to confirm eligibility

${ }^{b}$ Sorafenib arm only. Sorafenib patients contacted at Week 2 to assess treatment related toxicity and interrupt/modify the dose as necessary

'Disease progression, death, complete regression, unacceptable toxicity, patient responds to treatment and becomes eligible for surgical resection, liver transplantation or ablative therapy, lost to follow-up, patient's request for withdrawal

${ }^{d}$ Concomitant medication to be recorded from screening up to 30 days post-study conclusion, or until commencement of the next alternative therapy, whichever is earlier

e If either the Hepatitis B Surface Antigen (Hep Bsag) test or anti-HCV lgG test is positive, the other test will be optional. Hepatitis B Core Antibody lgG test is optional

fWomen of reproductive potential must have a negative pregnancy test before commencing treatment. Test to be repeated if pregnancy is suspected during the study

${ }^{9}$ Hepatic angiogram and ${ }^{99 m}$ Tc-MAA lung shunt study to be performed after randomisation and prior to treatment commencement only for SIRT arm group

${ }^{\mathrm{h}}$ The same radiological assessment method must be used throughout the study

i Assessment for tumour response rate to be done every 12 weeks from date of randomisation until first evidence of disease progression

Sorafenib-treated patients and 14 months for patients treated with Y-90 microspheres are assumed. This represents the minimum clinically meaningful difference to be detected.

Group-sequential methods are used to determine the sample size and study duration. Two interim analyses and a final analysis are planned to occur at equally spaced intervals after one-third, two-thirds and all of the planned number of deaths (events) have been reported. The planned sample size is determined assuming the use of a 2-sided log rank test with type I error of 0.05 and statistical power of $90 \%$. A dropout rate of up to $20 \%$ is also factored into the computations. The anticipated study duration is 5 years; with 3 years of accrual and 2 years follow-up. This corresponds to an estimated hazard rate of 0.67 with an expected 266 deaths at the end of the study

The number of patients required for randomisation to detect a clinically relevant difference in OS time with SIRT versus Sorafenib was determined to be 360 patients (180 patients in each treatment arm).

\section{Interim analyses}

Interim analyses for efficacy are planned after 33 and $65 \%$ of the information (corresponding to 87/266 and $174 / 266$ deaths) have been observed and using a critical $p$-value of $p \leq 0.0001$ for the first analysis and $p \leq 0.015$ for the second analysis These boundaries are obtained using the method of Lan and DeMets [38] and based on an overall significance level of $5 \%$. The final analysis will be performed after 266 reported deaths.

An independent Data Monitoring Committee will review the safety of the study and the results of the interim analyses and make appropriate recommendations to the trial steering committee. .

\section{Statistical analyses}

All analyses will be performed using the intention-totreat (ITT) principle where patients will be analysed according to their randomised group. The analysis of the primary outcome (OS) will be an unadjusted log rank test used to test and a proportional hazards model will be use to estimate the hazard ratio together with the corresponding $95 \%$ confidence intervals (CI). Time to event curves (for OS and PFS) will be displayed using the method of Kaplan-Meier.

The tumour response rate, disease control rate and the rate of down-staging to surgical resection, radiofrequency ablation or liver transplantation compared between treatments using appropriate tests for proportions

HRQoL will be analysed using generalised estimating equations assuming a common (exchangeable/compound symmetric) correlation structure, following the guidelines of the EQ-5D questionnaire.

A Landmark analysis will be performed at 2-months post-randomization comparing patients classified into four groups: Those randomised to Sorafenib and (i) but did not receive $80 \%$ of scheduled dose since randomization; (ii) those receiving at least $80 \%$ of the scheduled dose; and, those randomized to SIRT therapy and (iii) did not receive the therapy; (iv) those who receiving the SIRT therapy within the first two months of randomization [39]. This analysis will be repeated using 40 and $60 \%$ scheduled doses since randomization for defining groups (i) and (ii). These comparisons will be performed for the primary and secondary outcomes. Patients who died or discontinued the study before 2months of randomization will not be included from the analysis. Additional sub-group analyses will be performed based on patients' baseline characteristics such as presence or absence of portal vein thrombosis, BCLC 
stage, prior HCC treatment, hepatitis status, ECOG performance status, tumour size ( $\leq 50 \%$ of liver, $>50 \%$ of liver), age ( $<65$ years, $\geq 65$ year), and gender.

As the SIRT therapy is a local treatment, treatment effect of progression in the liver as the first event will be investigated using a competing risk analysis. In this analysis death or progression outside the liver as the first event will be considered as a competing risk for liver progression. The method of Gray [40] will be used to compare groups with hazard ratios and $95 \% \mathrm{CI}$ estimated from the proportional hazards approach detailed by Fine and Gray [41]. Time to liver progression in the two groups will be displayed using cumulative incidence curves.

Toxicity will be reported according to NCI CTCAE Version 4.02 criteria.

\section{Discussion}

The SIRveNIB trial will compare the efficacy and safety of SIRT with yttrium-90 resin microspheres with that of Sorafenib in the treatment of locally advanced HCC. To the authors' knowledge, no prospective, randomized controlled trials have been published comparing these treatment modalities in this patient population. Another study of similar design is ongoing in a European population, where the aetiology of HCC is different from that of the Asia-Pacific [30].

Sorafenib has been chosen as the control in the SIRveNIB trial as the current most effective systemic treatment for patients with unresectable advanced HCC, SIRT with resin microspheres has also demonstrated efficacy in advanced HCC [14, 22, 28, 42, 43].

In the SIRveNIB trial, OS has been chosen as the primary endpoint as it is a more robust measure than PFS, and the SHARP trial demonstrated the efficacy of Sorafenib based on this criterion. Moreover, the kinetics of tumour progression, as assessed from imaging techniques, is different between SIRT and Sorafenib, rendering OS the best option for comparison between arms in this trial. A European study with similar inclusion criteria is currently ongoing that compares Sorafenib with SIRT in patients with advanced HCC [30], and could be used for meta-analysis in the future.

In addition to efficacy analyses, the SIRveNIB trial enables comparison of the toxicity caused by Sorafenib versus SIRT in patients with locally advanced HCC. This is important as the cardiovascular toxicity of Sorafenib has been highlighted in a meta-analysis of cancer patients (predominantly renal carcinoma) [44], but was not a common complication in the SHARP study [12].

Limitations to the SIRveNIB study design have been addressed where feasible. While blinding is not possible due to the treatment methods, the potential biases caused by the lack of blinding have been minimised by the choice of OS as a robust primary endpoint.
The results from the SIRveNIB trial will impact clinical practice. A definitive randomised controlled trial comparing the two most promising therapies in locallyadvanced HCC should help determine the optimal treatment modality in this indication, or may help identify populations that are best suited to either therapy. In addition, the data generated from this study will determine the role of SIRT in in future consensus guidelines. The study will also pave the way for future trials in combined modality therapies in HCC.

\section{Trial status}

The SIRveNIB trial is currently ongoing. Patient recruitment closed on 25 May 2016 with a total of 360 participants randomised. The final analysis will be triggered after mortality reaches 266 .

\section{Abbreviations \\ 99mTc: Technetium-99 m; AASLD: American Association for the Study of Liver Diseases; ALP: Alkaline phosphatase; ALT: Alanine aminotransferase; AST: Aspartate transaminase; BCLC: Barcelona clinic liver cancer; BOR: Best overall response; Cl: Confidence interval; CR: Complete response; $C$ : Computed tomography; ECOG: Eastern Cooperative Oncology Group; HCC: Hepatocellular carcinoma; HRQOL: Health-related quality of life; INR: International normalised ratio; ITT: Intention to treat; MRI: Magnetic resonance imaging; NCI CTCAE: National Cancer Institute Common Terminology Criteria for Adverse Events; OS: Overall survival; PFS: Progression-free survival; PR: Partial response; PVT: Portal vein thrombosis; RECIST: Response Evaluation Criteria in Solid Tumours; SARAH: SorAfenib versus Radioembolisation in Advanced Hepatocellular carcinoma; SHARP: Sorafenib Hepatocellular carcinoma Assessment Randomized Protocol; SIRT: Selective Internal Radiation Therapy; SIRveNIB: Selective internal radiation therapy (SIRT) VErsus SorafeNIB in locally advanced hepatocellular carcinoma; TTP: Time to progression; ULN: Upper limit of normal}

\section{Acknowledgements}

We thank all the investigators involved in the SIRveNIB trial: Tjakra Wibawa Manuaba, LA Lesmana, Jong Yun Won, Hyun Ki Yoon, Kim Yun Hwan, Ho Seong Han, Si Hyun Bae, Aloysius Raj, Yoong Boon Koon, Law Chiong Soon, Ariunaa Khasbazar, Khin Maung Win, Adam Bartlett, Rolley Lobo, Catherine Teh, Ian Cua, Janus Ong, Stephen Chang, Tan Tzu Jen, Chanisa Chotipanich, Hung Chien Fu, Liang Po Chin, Lee Rheun Chuan, Peng Cheng Yuan, Kenneth Kok Yuh Yen. The authors would like to thank Singapore Clinical Research Institute for help in managing the trial operations and data management. The authors acknowledge the editorial assistance provided by Martin Gilmour of ESP Bioscience (Crowthorne, UK) funded by Sirtex Medical Limited, during the preparation of this manuscript.

\section{Funding}

This trial is funded by the National Medical Research Council, Singapore and Sirtex Medical Limited, Australia. Funders had no role in the trial design, the writing of the manuscript, or in the decision to submit the manuscript for publication. Funders will have no role in the collection, analysis, and interpretation of the data.

\section{Availability of data and materials}

The datasets generated during and/or analysed during the current study are not publicly available as the study is currently on-going and final results are not published. After the publication of the primary and key secondary results, datasets will be available from the corresponding author on reasonable request. The study data belongs to participating recruitment centres. Additional permission will be required from each of the recruitment centres to use patient data belonging to their centres.

\section{Authors' contributions}

MG and PKHC drafted the manuscript. MG, SBT and PKHC devised the study concept and design. PKHC obtained study funding. MG, PKHC, SPC, CHT, SBT, 
ASCL, PCC, ASWG, KHT, RHGL, BKPG, JSW, DCEN, KCS, WML have made substantial contribution to the study protocol. MG was responsible for statistics. MG, PKHC, SPC, CHT, SBT, ASCL, PCC, ASWG, KHT, RHGL, BKPG, JSW, DCEN, KCS, WML reviewed the manuscript and approved the final manuscript.

\section{Authors' information}

The authors choose not to include more information.

\section{Competing interests}

This trial is partially funded by Sirtex Medical Limited, Australia. PKHC reports receiving honorariums and research grants from Oncosil Pte Ltd, Psivida Pte Ltd, Sirtex Medical Limited, Bayer Pharma AG, Ipsen, Merck-Sharpe-Dome. DCEN reports being involved in research sponsored by Sirtex Medical Limited. RHGL reports being on the Sirtex SIRveNIB/SARAH Asia Pacific Advisory Board and is a proctor for Sirtex Medical Limited. BKPG reports receiving travel grants from Sirtex Medical Limited. SPC reports being an advisor for Bayer Pharma AG and receiving travel grants from Sirtex Medical Limited. ASHG reports receiving travel grants from Sirtex Medical Limited. KHT reports being a proctor for Sirtex Medical Limited and a country Principal Investigator for the Sirtex SIRT Registry and receiving conference travel grant from Sirtex Medical Limited. No other potential conflict of interest relevant to this work was reported.

\section{Consent for publication}

Not applicable.

\section{Ethics approval and consent to participate}

The trial protocol is approved by Sing Health Centralised Institutional Review Board (CIRB), Singapore (for National Cancer Centre Singapore and Singapore General Hospital) (CIRB Reference Number 2010/145/B) and each institutional review board of all participating sites: Medical and Health Research \& Ethics Committee in Brunei (Ref No: MHREC/MOH/2010/18(8)), the Committee of the Medical Research Ethics of the Faculty of Medicine, University of Indonesia (Ref No: 465/PT02.FK/ETIK/2010), Research and Development Unit, Medical Faculty University of Udayana/Sanglah Hospital Denpasar in Indonesia (Ref No: 605/Skrt/IX/2010), Asan Medical Centre in South Korea (Ref No: 2011-0155), Korea University Anam Hospital (Ref No: ED10274), Seoul National University Hospital (Ref No: E-1102/059-007), The Catholic University of Korea Seoul St. Mary's Hospital (Ref No: KC11EIGT0112), Yonsei University Health System, Severance Hospital, Institutional Review Board in South Korea (Ref No: 4-2010-0696), Joint Penang Independent Ethics Committee (JPEC) in Malaysia (Ref No:11-0026), Medical Ethics Committee University Malaya Medical Center in Malaysia (MECID No: 20149-541), Medical Ethics Committee of Ministry of Health, Mongolia (No 1), Institutional Review Board Yangon Gl and Liver Center in Myanmar (Ref No: N.A.), Northern Y Regional Ethics Committee in New Zealand (Ref No: NTY/10/06/057/AM05), Institutional Ethics Review Committee St. Luke's Medical Center in Philippines (CT Tracking No: CT10012), Institutional Review Board The Medical City in Philippines (Ref No: N.A.), Makati Medical Center Institutional Review Board (Ref No: MMCIRB 2011-002), Davao Doctors Hospital Institutional Ethics Review Board (Ref No: N.A.), National Healthcare Group Domain-Specific Review Board (DSRB) in Singapore for (National University Hospital and Khoo Teck Puat Hospital) (DSRB Ref No: B/10/337), Institutional Review Board Taipei Veterans General Hospital in Taiwan (Ref No: 201012006MA), Research Ethics Committee B of the National Taiwan University Hospital (NTUH-REC No: 201010001D), Research Ethics Committee China Medical University \& Hospital in Taiwan (Protocol No./CMUH REC No.: AHCC06/DMR101-IRB1-280), Chang Gung Memorial Hospital in Taiwan (CGMF Case No.: 103-1622C (Original 992583A)), Committee on Human Rights Related to Research Involving Human Subject Chulabhorn Hospital in Thailand (Project No:15/2555) Patients giving consent for participation sign the ethically approved patient informed consent.

\section{Author details}

'Biostatistics, Singapore Clinical Research Institute, \#02-01, Nanos, 31 Biopolis Way, Singapore, Singapore. ${ }^{2}$ Centre for Quantitative Medicine, Duke-NUS Medical School, 8 College Road, Singapore, Singapore. ${ }^{3}$ Tampere Center for Child Health Research, University of Tampere and Tampere University Hospital, Tempere, Finland. ${ }^{4}$ Division of Medical Oncology, National Cancer Centre Singapore, 11 Hospital Drive, Singapore, Singapore. ${ }^{5}$ Division of
Oncologic Imaging, National Cancer Centre Singapore, 11 Hospital Drive, Singapore, Singapore. ${ }^{6}$ Office of Research, Singapore Health Services, 31 Third Hospital Avenue, \#03-03 Bowyer Block C, Singapore, Singapore. ${ }^{7}$ Clinical Sciences, Duke-NUS Medical School, 8 College Road, Singapore, Singapore. ${ }^{8}$ Department of Diagnostic Radiology, Singapore General Hospital, Outram Road, Singapore, Singapore. ${ }^{9}$ Department of

Hepato-pancreato-biliary and Transplant Surgery, Singapore General Hospital, Outram Road, Singapore, Singapore. ${ }^{10}$ Department of Nuclear Medicine and PET, Singapore General Hospital, Outram Road, Singapore, Singapore. ${ }^{11}$ Division of Surgical Oncology, National Cancer Centre Singapore, 11 Hospital Drive, Singapore, Singapore. ${ }^{12}$ Project Management, Singapore Clinical Research Institute, \#02-01, Nanos, 31 Biopolis Way, Singapore, Singapore. ${ }^{13}$ Office of Clinical, Academic and Faculty Affairs, Duke-NUS Medical School, 8 College Road Singapore, Singapore. ${ }^{14}$ Program in Translational and Clinical Liver Research, National Cancer Centre Singapore, Singapore, Singapore.

Received: 5 July 2016 Accepted: 13 October 2016

Published online: 07 November 2016

\section{References}

1. Venook AP, Papandreou C, Furuse J, de Guevara LL. The incidence and epidemiology of hepatocellular carcinoma: a global and regional perspective. Oncologist. 2010;15 Suppl 4:5-13.

2. McGlynn KA, Tsao L, Hsing AW, Devesa SS, Fraumeni Jr JF. International trends and patterns of primary liver cancer. Int I Cancer J Int du Cancer. 2001;94(2):290-6.

3. Llovet JM, Fuster J, Bruix J, Barcelona-Clinic Liver Cancer G. The Barcelona approach: diagnosis, staging, and treatment of hepatocellular carcinoma. Liver Transpl. 2004;10(2 Suppl 1):S115-20.

4. Hung H. Treatment modalities for hepatocellular carcinoma. Curr Cancer Drug Targets. 2005;5(2):131-8.

5. Poon D, Anderson BO, Chen LT, Tanaka K, Lau WY, Van Cutsem E, Singh H, Chow WC, Ooi LL, Chow P, et al. Management of hepatocellular carcinoma in Asia: consensus statement from the Asian Oncology Summit 2009. Lancet Oncol. 2009;10(11):1111-8.

6. Pawarode A, Tangkijvanich P, Voravud N. Outcomes of primary hepatocellular carcinoma treatment: an 8-year experience with 368 patients in Thailand. J Gastroenterol Hepatol. 2000;15(8):860-4.

7. Chow PK, Tai BC, Tan CK, Machin D, Win KM, Johnson PJ, Soo KC, AsianPacific Hepatocellular Carcinoma Trials G. High-dose tamoxifen in the treatment of inoperable hepatocellular carcinoma: a multicenter randomized controlled trial. Hepatology (Baltimore, Md). 2002;36(5):1221-6.

8. Cabbibo G, Enea M, Latteri F, Genco C, Craxi A, Cammá C. Survival of unresectable hepatocellular carcinoma: a meta-anlyasis of the control arms of 28 randomized trials. J Hepatol. 2009;50(Supplement 1):S285.

9. Hsu C, Shen YC, Cheng CC, Hu FC, Cheng AL. Geographic difference in survival outcome for advanced hepatocellular carcinoma: implications on future clinical trial design. Contemp Clin Trials. 2010;31(1):55-61.

10. Llovet JM, Di Bisceglie AM, Bruix J, Kramer BS, Lencioni R, Zhu AX, Sherman M, Schwartz M, Lotze M, Talwalkar J, et al. Design and endpoints of clinical trials in hepatocellular carcinoma. J Natl Cancer Inst. 2008;100(10):698-711.

11. Nowak AK, Chow PK, Findlay M. Systemic therapy for advanced hepatocellular carcinoma: a review. Eur J Cancer. 2004:40(10):1474-84.

12. Llovet JM, Ricci S, Mazzaferro V, Hilgard P, Gane E, Blanc JF, de Oliveira AC, Santoro A, Raoul JL, Forner A, et al. Sorafenib in advanced hepatocellular carcinoma. N Engl J Med. 2008;359(4):378-90.

13. Cheng AL, Kang YK, Chen Z, Tsao CJ, Qin S, Kim JS, Luo R, Feng J, Ye S, Yang TS, et al. Efficacy and safety of sorafenib in patients in the Asia-Pacific region with advanced hepatocellular carcinoma: a phase III randomised, double-blind, placebo-controlled trial. Lancet Oncol. 2009;10(1):25-34.

14. Kang Y, Guan Z, Chen Z, Tsao C, Qin S, Kim JS, Burrock K, Zou J, Voliotis D, Cheng A. Sorafenib is effective in patients from the Asia Pacific region with hepatocellular carcinoma (HCC): Subgroup analysis of macroscopic vascular invasion (MVI), extrahepatic spread (EHS), and ECOG performance status. Ann Oncol. 2008;19(Supplement 8):177.

15. Vente MA, Wondergem M, van der Tweel I, van den Bosch MA, Zonnenberg BA, Lam MG, van Het Schip AD, Nijsen JF. Yttrium-90 microsphere radioembolization for the treatment of liver malignancies: a structured meta-analysis. Eur Radiol. 2009;19(4):951-9. 
16. Kulik LM, Carr BI, Mulcahy MF, Lewandowski RJ, Atassi B, Ryu RK, Sato KT, Benson 3rd A, Nemcek Jr AA, Gates VL, et al. Safety and efficacy of 90Y radiotherapy for hepatocellular carcinoma with and without portal vein thrombosis. Hepatology (Baltimore, Md). 2008;47(1):71-81.

17. Kulik LM, Atassi B, van Holsbeeck L, Souman T, Lewandowski RJ, Mulcahy MF, Hunter RD, Nemcek Jr AA, Abecassis MM, Haines 3rd KG, et al. Yttrium90 microspheres (TheraSphere) treatment of unresectable hepatocellular carcinoma: downstaging to resection, RFA and bridge to transplantation. J Surg Oncol. 2006;94(7):572-86.

18. Sangro B, Bilbao Jl, Boan J, Martinez-Cuesta A, Benito A, Rodriguez J, Panizo A, Gil B, Inarrairaegui M, Herrero I, et al. Radioembolization using 90Y-resin microspheres for patients with advanced hepatocellular carcinoma. Int J Radiat Oncol Biol Phys. 2006;66(3):792-800.

19. Young JY, Rhee TK, Atassi B, Gates VL, Kulik L, Mulcahy MF, Larson AC, Ryu RK, Sato KT, Lewandowski RJ, et al. Radiation dose limits and liver toxicities resulting from multiple yttrium-90 radioembolization treatments for hepatocellular carcinoma. J Vasc Interv Radiol. 2007;18(11):1375-82.

20. Sangro B, Carpanese L, Cianni R, Golfieri R, Gasparini D, Ezziddin S, Paprottka PM, Fiore F, Van Buskirk M, Bilbao J, et al. Survival after yttrium-90 resin microsphere radioembolization of hepatocellular carcinoma across Barcelona clinic liver cancer stages: a European evaluation. Hepatology (Baltimore, Md). 2011;54(3):868-78.

21. Hilgard P, Hamami M, Fouly AE, Scherag A, Muller S, Ertle J, Heusner T, Cicinnati VR, Paul A, Bockisch A, et al. Radioembolization with yttrium-90 glass microspheres in hepatocellular carcinoma: European experience on safety and long-term survival. Hepatology (Baltimore, Md). 2010;52(5):1741-9.

22. Salem R, Lewandowski RJ, Mulcahy MF, Riaz A, Ryu RK, Ibrahim S, Atassi B, Baker T, Gates V, Miller FH, et al. Radioembolization for hepatocellular carcinoma using Yttrium-90 microspheres: a comprehensive report of longterm outcomes. Gastroenterology. 2010;138(1):52-64.

23. Golfieri R, Mosconi C, Cappelli A, Giampalma E, Galaverni MC, Pettinato C, Renzulli M, Monari F, Angelelli B, Pini P, et al. Efficacy of radioembolization according to tumor morphology and portal vein thrombosis in intermediate-advanced hepatocellular carcinoma. Future Oncol. 2015;11(23):3133-42.

24. Gramenzi A, Golfieri R, Mosconi C, Cappelli A, Granito A, Cucchetti A, Marinelli S, Pettinato C, Erroi V, Fiumana S, et al. Yttrium-90 radioembolization vs sorafenib for intermediate-locally advanced hepatocellular carcinoma: a cohort study with propensity score analysis. Liver Int. 2015;35(3):1036-47.

25. Khor AY, Toh Y, Allen JC, Ng DC, Kao YH, Zhu G, Choo SP, Lo RH, Tay KH, Teo JY, et al. Survival and pattern of tumor progression with yttrium-90 microsphere radioembolization in predominantly hepatitis B Asian patients with hepatocellular carcinoma. Hepatol Int. 2014;8(3):395-404.

26. Cho YY, Lee M, Kim HC, Chung JW, Kim YH, Gwak GY, Bae SH, Kim do Y, Heo J, Kim YJ. Radioembolization is a safe and effective treatment for hepatocellular carcinoma with portal vein thrombosis: a propensity score analysis. PLoS ONE. 2016;11(5):e0154986.

27. de la Torre MA, Buades-Mateu J, de la Rosa PA, Lué A, Bustamante FJ, Serrano MT, Testillano M, Lorente S, Arenas Jl, Gil C, Iñarrairaegui M, Sangro B. A comparison of survival in patients with hepatocellular carcinoma and portal vein invasion treated by radioembolization or sorafenib. Liver Int. 2016;36(8):1206-12.

28. Lewandowski RJ, Kulik LM, Riaz A, Senthilnathan S, Mulcahy MF, Ryu RK, Ibrahim SM, Sato KT, Baker T, Miller FH, et al. A comparative analysis of transarterial downstaging for hepatocellular carcinoma: chemoembolization versus radioembolization. Am J Transplant. 2009;9(8):1920-8.

29. Sangro B, Ettorre GM, Cianni R, Gasparini D, Golfieri R, Ezzidin S, Kolligs FT, Izzo F, Van Buskirk M. Survival and tolerability following 90Y-resin microsphere radioembolisation in patients with unresectable BCLC stage C hepatocellular carcinoma (HCC). J Hepatol. 2011;54 Suppl 1:S262-3.

30. Vilgrain V, Abdel-Rehim M, Sibert A, Ronot M, Lebtahi R, Castera L, Chatellier $\mathrm{G}$, Group ST. Radioembolisation with yttrium 90 microspheres versus sorafenib for treatment of advanced hepatocellular carcinoma (SARAH): study protocol for a randomised controlled trial. Trials. 2014;15:474.

31. Bruix J, Takayama T, Mazzaferro V, Chau GY, Yang J, Kudo M, Cai J, Poon RT, Han KH, Tak WY, et al. Adjuvant sorafenib for hepatocellular carcinoma after resection or ablation (STORM): a phase 3, randomised, double-blind, placebo-controlled trial. Lancet Oncol. 2015;16(13):1344-54.

32. Kennedy AS, Kleinstreuer C, Basciano CA, Dezarn WA. Computer modeling of yttrium-90-microsphere transport in the hepatic arterial tree to improve clinical outcomes. Int J Radiat Oncol Biol Phys. 2010;76(2):631-7.
33. Ho S, Lau WY, Leung TW, Chan M, Ngar YK, Johnson PJ, Li AK. Partition model for estimating radiation doses from yttrium-90 microspheres in treating hepatic tumours. Eur J Nucl Med. 1996;23(8):947-52.

34. Bruix J, Sherman M. Management of hepatocellular carcinoma: an update. Hepatology. 2011;53:1020-2.

35. Eisenhauer EA, Therasse P, Bogaerts J, Schwartz LH, Sargent D, Ford R, Dancey J, Arbuck S, Gwyther S, Mooney M, et al. New response evaluation criteria in solid tumours: revised RECIST guideline (version 1.1). Eur J Cancer. 2009;45(2):228-47.

36. National Institute of Health National Cancer Institute. Common Terminology Criteria for Adverse Events v 4.02 [http://evs.nci.nih.gov/ ftp1/CTCAE/Archive/CTCAE_4.02_2009-09-15_QuickReference_5x7_ Locked.pdf]. Accessed 24 Oct 2016.

37. Sangro B, Carpanese L, Cianni R, Golfieri R, Gasparini D, Ezziddin S, Paprottka PM, Fiore F, Van Buskirk M, Bilbao Jl, Ettorre GM, Salvatori R, Giampalma E, Geatti O, Wilhelm K, Hoffmann RT, Izzo F, Iñarrairaegui M, Maini CL, Urigo C, Cappelli A, Vit A, Ahmadzadehfar H, Jakobs TF, Lastoria S. European Network on Radioembolization with Yttrium-90 Resin Microspheres (ENRY). Survival after yttrium-90 resin microsphere radioembolization of hepatocellular carcinoma across Barcelona clinic liver cancer stages: a European evaluation. Hepatology. 2011;54(3):868-78.

38. Lan KKG, DeMets DL. Discrete sequential boundaries for clinical trials. Biometrika. 1983;70:659-63.

39. Anderson JR, Cain KC, Gelber RD, Gelman RS. Analysis and interpretation of the comparison of survival by treatment outcome variables in cancer clinical trials. Cancer Treat Rep. 1985;69(10):1139-46.

40. Gray RJ. A class of K-sample tests for comparing the cumulative incidence of a competing risk. Ann Stat. 1988;16:1141-54.

41. Fine JP, Gray RJ. A proportional hazards model for the subdistribution of a competing Risk. J Am Stat Assoc. 1999;94(446):496-509.

42. Lau WY, Leung WT, Ho S, Leung NW, Chan M, Lin J, Metreweli C, Johnson P, Li AK. Treatment of inoperable hepatocellular carcinoma with intrahepatic arterial yttrium-90 microspheres: a phase I and I| study. Br J Cancer. 1994;70(5):994-9

43. Sangro B, Carpanese L, Cianni R, Golfieri R, Gasparini D, Ezzidin S, Hoffman R, Fiore F, on behalf of the European Network on Radioembolization Using Y90 Microspheres (ENRY). European multicenter evaluation of survival for patients with hepatocellular carcinoma ( $\mathrm{HCC}$ ) treated by radioembolization with $90 \mathrm{y}$ labeled resin microspheres. J Clin Oncol 2010;28(no. 15_suppl):4027.

44. Wu S, Chen JJ, Kudelka A, Lu J, Zhu X. Incidence and risk of hypertension with sorafenib in patients with cancer: a systematic review and metaanalysis. Lancet Oncol. 2008;9(2):117-23.

\section{Submit your next manuscript to BioMed Central and we will help you at every step:}

- We accept pre-submission inquiries

- Our selector tool helps you to find the most relevant journal

- We provide round the clock customer support

- Convenient online submission

- Thorough peer review

- Inclusion in PubMed and all major indexing services

- Maximum visibility for your research

Submit your manuscript at www.biomedcentral.com/submit
Biomed Central 